\title{
Prevalence of Supranormal Pulmonary Function Test Values Between a Military and Nonmilitary Cohort
}

\author{
Anthony A Cochet Capt USAF MC, Pedro F Lucero LTC MC USA, \\ Lisa L Zacher COL MC USA, and Michael J Morris MD
}

\begin{abstract}
BACKGROUND: The study objective was to determine differences in the proportion of supranormal pulmonary function tests (PFTs) between active duty (AD) military personnel and a similar non-active duty (non-AD) population. Given the emphasis on cardiovascular fitness in the military, it has been hypothesized that regular exercise in this cohort leads to an increased proportion of supranormal PFTs. We hypothesized that a comparison of PFTs would identify no differences in the ratio of supranormal to normal PFTs between the AD and non-AD populations. METHODS: A retrospective chart review was conducted of all PFT studies at the Brooke Army Medical Center from 2006 to 2011. Studies were included with either an $\mathrm{FVC}$ or $\mathrm{FEV}_{1}>110 \%$ of predicted, with both values $>100 \%$ of predicted. A comparative analysis was performed for patients between 18 and 50 years of age based on AD status. Further analysis was performed on all ages to determine the distribution of supranormal findings in the entire study population. RESULTS: A total of 16,600 interpreted PFTs were queried. Of those, 4,303 (31.6\%) were AD patients, and 9,306 (68.4\%) were non-AD patients. From all of the PFTs reviewed, a total of $912(6.7 \%)$ were identified as supranormal. When further analyzed, $381(9.4 \%)$ of AD patients 18-50 years old were supranormal, 175 (12.4\%) of non-AD patients 18-50 years old were supranormal, and $356(4.7 \%)$ of non-AD patients older than 50 years were supranormal. CONCLUSIONS: This study revealed no significant difference in the proportion of supranormal-to-normal PFTs in an AD versus non-AD duty population of the same age range. Based on these findings, no assumption should be made that supranormal PFTs are more common in military personnel. Interpretation of normal PFTs in AD personnel undergoing evaluation should not differ from that in any typical patient. Key words: pulmonary function testing; military personnel; supranormal values. [Respir Care 2014;59(5):749-755. () 2014 Daedalus Enterprises]
\end{abstract}

\section{Introduction}

Dyspnea is a frequently evaluated complaint among the active duty (AD) population of the United States military. In part, military personnel may be referred for clinical

\footnotetext{
Captain Cochet is affiliated with the Department of Medicine, Brooke Army Medical Center, Fort Sam Houston, Texas. Lieutenant Colonel Lucero, Colonel Zacher, and Dr Morris are affiliated with the Pulmonary/ Critical Care Service, Department of Medicine, Brooke Army Medical Center, Fort Sam Houston, Texas.
}

The opinions in this manuscript do not constitute endorsement by Brooke Army Medical Center, the United States Army Medical Department, the United States Army Office of the Surgeon General, the Department of the Army, Department of Defense, or the United States Government of the information contained therein. evaluation due to their inability to meet the physical requirements of military service and specifically the standards for a timed physical fitness run. Although asthma and exercise-induced bronchospasm are often the cause of exertional symptoms, many initial clinical evaluations based on pulmonary function testing (PFT) and chest imaging are negative. Twenty-five percent of AD military

\footnotetext{
Dr. Morris is a paid speaker for Spiriva by Pfizer/Boehringer Ingelheim. The other authors have declared no conflicts of interest.

Correspondence: Michael J Morris MD, Pulmonary/Critical Care Service (MCHE-MDP), Brooke Army Medical Center, 3551 Roger Brooke Drive, Fort Sam Houston, TX 78234. E-mail: michael.j.morris34.civ@mail.mil.
}

DOI: $10.4187 /$ respcare.02112 
personnel with complaints of exertional dyspnea had a negative comprehensive evaluation. ${ }^{1}$ Given the recent emphasis on post-deployment respiratory symptoms and the possible relationship with environmental exposures such as sand storms and burn pits, many military personnel being evaluated for respiratory symptoms are found to have normal baseline PFTs. ${ }^{2,3}$ Some clinicians have theorized that the $\mathrm{AD}$ military population, with a high level of emphasis on regular physical fitness compared with their non-AD counterparts, has a larger proportion of supranormal PFT values. This has lead to a supposition that a "normal" spirometry in an AD service member presenting with dyspnea actually reflects a decrement in function and underlying lung disease. ${ }^{3}$ Although spirometry reference equations such as National Health and Nutrition Examination Survey (NHANES) III establish both an upper and lower limit for normal, the upper limit of normal is not routinely calculated on spirometry reports. How does a clinician interpret spirometry either in those patients referred for a baseline study due to military occupational exposures or in those symptomatic individuals presenting with cough, dyspnea, or other respiratory complaints other than with established population guidelines?

Intense aerobic training does have a direct impact on overall cardiovascular function, muscle strength and endurance, and hematologic indices. ${ }^{4}$ However, data are inconclusive regarding the change in lung function in highlevel aerobic performers. Studies comparing athletes and individuals in high-performance professions with untrained control groups provide little evidence that high demand of lung function changes the underlying PFT values. ${ }^{5}$ The results of these studies led many investigators to question whether the minor increases in lung function found in conditioned versus non-conditioned subjects were induced by training or present prior to training. Conversely, several studies of elite athletes for the diagnosis of exercise-induced bronchospasm have noted elevated baseline values in this population. ${ }^{6,7}$ Given the current lack of evidence supporting the correlation between increased levels of fitness and supranormal PFTs in elite athletes, the suggestion that the military population would comprise more supranormal PFT values than the general population has not been investigated. Although many members of the military achieve and maintain a high level of physical fitness, the average military member is not a highly conditioned elite athlete. We hypothesized that a comparison of PFT data from both $\mathrm{AD}$ military and non-AD beneficiaries would not demonstrate an increase in supranormal values.

\section{Methods}

This study was conducted as a retrospective review of Department of Defense electronic medical records after obtaining written approval from the local institutional re-

\section{QUICK LOOK}

\section{Current knowledge}

Dyspnea is a frequent complaint among the active duty population of the United States military. Military personnel may be referred for clinical evaluation due to their inability to meet the physical requirements of military service, specifically the standards for a timed physical fitness run.

\section{What this paper contributes to our knowledge}

The physical requirements of military service do not alter the normal distribution of pulmonary function results. There was no difference in pulmonary function test results between active duty military personnel and a similar cohort of civilians.

view board. The electronic database repository for all PFT studies conducted at the Brooke Army Medical Center was queried from 2006 to 2011. All studies were performed on a spirometer (SensorMedics Vmax-22, CareFusion, San Diego, California), which was calibrated on a daily basis following the manufacturer's recommendations. Individual spirometry examinations were reviewed, and those with an elevated $\mathrm{FVC}$ or $\mathrm{FEV}_{1}>110 \%$ of predicted (based on NHANES III reference values) were identified. ${ }^{8}$ To qualify for inclusion in this study, both the $\mathrm{FEV}_{1}$ and $\mathrm{FVC}$ were required to be $>100 \%$ of predicted. Spirometry reports from our laboratory do not calculate the upper limit of normal based on CI, and the percent of predicted was used as a surrogate to compare populations. Studies that did not meet American Thoracic Society guidelines for acceptability and repeatability were excluded from further analysis. Specific note was also made for patients with either $\mathrm{FEV}_{1}$ or $\mathrm{FVC}>120 \%$ of predicted. The percentage of percent-of-predicted values (110\% and $120 \%)$ that were above the calculated 95\% CI based on the NHANES III upper limit of normal for $\mathrm{FEV}_{1}$ and $\mathrm{FVC}$ was also determined for the included studies. From these studies, the following information was obtained: (1) patient demographics (age, gender, ethnicity, and height); (2) patient military status (AD, retired, or military dependent); (3) spirometry results (actual, predicted, and $\%$ of predicted) to include $\mathrm{FEV}_{1}, \mathrm{FVC}$, and $\mathrm{FEV}_{1} / \mathrm{FVC}$; and (4) if performed, total lung capacity (TLC), residual volume (RV), and diffusing capacity for carbon monoxide $\left(\mathrm{D}_{\mathrm{LCO}}\right)$.

Results were divided into 3 groups of patients for analysis: (1) AD military 18-50 years old, (2) non-AD patients 18-50 years old, and (3) military retirees or dependents 51-90 years old. The percentage of studies meeting the inclusion criteria was calculated from the overall number of studies performed based on diagnostic procedure codes 
Table 1. Patient Demographics

\begin{tabular}{|c|c|c|c|c|}
\hline & $\begin{array}{c}\mathrm{AD} \\
(18-50 \mathrm{y})\end{array}$ & $\begin{array}{l}\text { Non-AD } \\
(18-50 \text { y) }\end{array}$ & $\begin{array}{l}\text { Non-AD } \\
(50-90 \text { y) }\end{array}$ & Total \\
\hline$n>110 \%$ & $381(7.3 \%)$ & $175(9.7 \%)$ & $356(3.7 \%)$ & $912(5.5 \%)$ \\
\hline$n>120 \%$ & $93(1.7 \%)$ & $43(2.3 \%)$ & $112(1.2 \%)$ & $248(1.5 \%)$ \\
\hline Gender (male/female) & $219 / 162(57 / 43 \%)$ & $25 / 150(14 / 86 \%)$ & $124 / 232(35 / 65 \%)$ & $368 / 544(40 / 60 \%)$ \\
\hline Age (y) & $31.6 \pm 9.9$ & $35.5 \pm 10.8$ & $65.5 \pm 10.8$ & $45.6 \pm 19.1$ \\
\hline Height (cm) & $170.8 \pm 11.3$ & $165.1 \pm 8.6$ & $163.6 \pm 9.5$ & $166.9 \pm 10.7$ \\
\hline $\begin{array}{l}\text { Demographics for overall grou } \\
\mathrm{AD}=\text { active duty } \\
\text { Non- } \mathrm{AD}=\text { non-active duty }\end{array}$ & by patient groups (active & duty) & & \\
\hline
\end{tabular}

obtained for the pulmonary clinic during the study years. Values were calculated for $\mathrm{AD}$ and non-AD patients by groups and age ranges.

Statistical analysis was performed using commercially available software (SPSS 16 and SAS 9.3, SPSS, Chicago, Illinois). Statistical comparison of the three groups was done with a one-way analysis of variance for the following variables: FVC (\% predicted), $\mathrm{FEV}_{1}$ ( $\%$ predicted), and $\mathrm{FEV}_{1} / \mathrm{FVC}$ (actual). Post hoc analysis was performed if the primary analysis failed to reach significance. Additional analysis included differences between groups based on RV (\% predicted), TLC ( $\%$ predicted), and $\mathrm{D}_{\mathrm{LCO}}(\%$ predicted $)$ values. Direct comparison of the $18-50$ $\mathrm{AD}$ and non-AD groups was performed using a paired $t$ test assuming equal variance. A final analysis was also performed to evaluate for any differences in PFT values based on gender or ethnicity. To compare the actual FEV and FVC for AD and non-AD across ages 18-50 y, a Z score was calculated for all patients. The $\mathrm{Z}$ score was calculated by taking each patient's absolute $\mathrm{FEV}_{1}$ and FVC measures, subtracting the mean, and dividing by the SD, with respect to their gender and age group (18-20, 21-30, 31-40, and 41-50 y). The $\mathrm{Z}$ scores for AD and non-AD were then compared using a $t$ test for both the $\mathrm{FEV}_{1}$ and FVC measures.

\section{Results}

A total of 16,600 PFTs performed at the Brooke Army Medical Center between 2006 and 2011 were queried in this study. Of those, $32 \%$ were identified as AD patients, and the remaining $68 \%$ were non-AD patients, either military retirees or dependent family members. Further division of the non-AD duty patients identified by the 18-50- and 51-90-year age groups identified the percentages as $11-57 \%$. The number and percentage of supranormal spirometry values for each group and the total cohort are shown in Table 1. For the total cohort, 912 (5.5\%) were found to have supranormal values at $110 \%$ of predicted, and 248 (1.5\%) had either $\mathrm{FEV}_{1}$ or $\mathrm{FVC}>120 \%$ of predicted. The highest percentage of supranormal values at $9.7 \%$ was found to be in the 18-50-year-old non-AD group. The remaining demographic information is also given in Table 1. Notably, the overall gender distribution was $40 \%$ male and $60 \%$ female, but the AD group had a higher percentage of males at $57 \%$. The percentage of military retirees (vs dependents) in the 50-90-year age group was $41 \%$.

The PFT values for each group are shown in Table 2. Eighty-nine percent of studies with FVC $>120 \%$ also exceeded $95 \%$ CI, whereas only $32 \%$ exceeded $95 \% \mathrm{CI}$ at $110 \%$ of predicted. For $\mathrm{FEV}_{1}>120 \%$ and $110 \%$ of predicted, the percentage of studies above $95 \%$ CI were $78 \%$ and $26 \%$, respectively. When all 3 groups were analyzed and found to have a normal distribution, a significant difference for $\mathrm{FEV}_{1}$ (\% predicted) is shown, which can be accounted for by the higher $\mathrm{FEV}_{1}$ in the 50-90-year age group. Further subset analysis using a paired $t$ test showed no statistical difference between the 18-50-year-old AD and non-AD groups for $\mathrm{FEV}_{1}(\%$ predicted $)(P=.927)$. The differences seen in $\mathrm{FEV}_{1}$ account for the significant difference seen in $\mathrm{FEV}_{1} / \mathrm{FVC}$ across all 3 groups; no difference exists between the 18-50-year-old AD and non-AD groups $(P=.736)$ when directly compared. Analysis of TLC, RV, and $\mathrm{D}_{\mathrm{LCO}}$ as shown in Table 2 also showed a significant difference for TLC $(P<.005)$ and $\mathrm{D}_{\mathrm{LCO}}$ $(P<.005)$, which can be accounted for by the decrease in both values in the 51-90-year age group.

To further define the distribution of PFT values within this cohort, $\mathrm{Z}$ scores were calculated for the AD group $(18-50 \mathrm{y})$ and the non-AD group $(18-50 \mathrm{y})$ by gender and across age ranges. The results are shown in Table 3 and demonstrate statistical differences in actual $\mathrm{FEV}_{1}$ and $\mathrm{FVC}$ between the $\mathrm{AD}$ and non-AD groups $(P<.001)$. However, when calculated using $\mathrm{Z}$ scores, there is normal distribution of both $\mathrm{FEV}_{1}$ and FVC, with $P=.15$ and .36 , respectively.

Distribution of the supranormal values was further analyzed by year of study and age ranges. Figure 1 shows the distribution of supranormal PFTs based on year of study. 
PFT Values in Military and Nonmilitary Cohorts

Table 2. Comparison of Pulmonary Function Test Values for Active Duty and Non-Active Duty Groups

\begin{tabular}{|c|c|c|c|c|c|}
\hline & $\begin{array}{c}\mathrm{AD} \\
(18-50 \mathrm{y})\end{array}$ & $\begin{array}{l}\text { Non-AD } \\
(18-50 \text { y) }\end{array}$ & $\begin{array}{l}\text { Non-AD } \\
(50-90 \text { y) }\end{array}$ & All Patients & $P$ \\
\hline Spirometry & $n=381$ & $n=175$ & $n=356$ & $n=912$ & \\
\hline $\mathrm{FEV}_{1}$ (actual) & $4.15 \pm 0.83$ & $3.49 \pm 0.65$ & $2.85 \pm 0.78$ & $3.52 \pm 0.97$ & $<.001$ \\
\hline $\mathrm{FEV}_{1}(\%$ predicted $)$ & $112.9 \pm 8.3$ & $112.8 \pm 9.1$ & $116.3 \pm 10.8$ & $114.2 \pm 9.6$ & $<.001$ \\
\hline FVC (actual) & $5.10 \pm 1.03$ & $4.31 \pm 0.80$ & $3.68 \pm 0.99$ & $4.40 \pm 1.17$ & $<.001$ \\
\hline FVC (\% predicted) & $115.3 \pm 7.6$ & $115.7 \pm 9.6$ & $114.4 \pm 9.6$ & $115.0 \pm 8.8$ & .2 \\
\hline $\mathrm{FEV}_{1} / \mathrm{FVC}$ & $0.82 \pm 0.05$ & $0.81 \pm 0.05$ & $0.78 \pm 0.06$ & $0.8 \pm 0.06$ & $<.001$ \\
\hline Full PFTs & $n=60$ & $n=24$ & $n=103$ & $n=187$ & \\
\hline TLC (actual) & $6.51 \pm 1.25$ & $5.29 \pm 0.90$ & $5.12 \pm 0.87$ & $5.70 \pm 1.31$ & $<.001$ \\
\hline TLC (\% predicted) & $110.6 \pm 15.4$ & $110.4 \pm 14.1$ & $103.9 \pm 12.1$ & $106.9 \pm 14.1$ & $<.005$ \\
\hline RV (actual) & $1.31 \pm 0.76$ & $1.24 \pm 0.38$ & $1.64 \pm 0.57$ & $1.48 \pm 0.65$ & .001 \\
\hline RV (\% predicted) & $80.7 \pm 51.2$ & $78.6 \pm 24.8$ & $79.2 \pm 25.2$ & $79.6 \pm 35.0$ & .96 \\
\hline $\mathrm{D}_{\mathrm{LCO}}$ (actual) & $29.16 \pm 6.47$ & $23.08 \pm 5.56$ & $18.68 \pm 5.47$ & $22.61 \pm 7.78$ & $<.001$ \\
\hline $\mathrm{D}_{\mathrm{LCO}}(\%$ predicted $)$ & $83.4 \pm 14.4$ & $82.7 \pm 15.8$ & $74.5 \pm 16.7$ & $78.4 \pm 18.3$ & $<.005$ \\
\hline 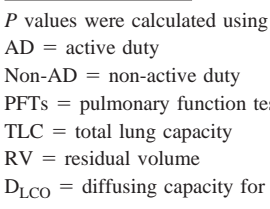 & is of variance & & & & \\
\hline
\end{tabular}

Table 3. Z Score Analysis

\begin{tabular}{|c|c|c|c|}
\hline Variable & Non-AD & $\mathrm{AD}$ & $P$ \\
\hline \multicolumn{3}{|l|}{ Actual FEV 1} & $<.001 *$ \\
\hline$n$ & 175 & 381 & \\
\hline Mean \pm SD & $3.49 \pm 0.65$ & $4.15 \pm 0.83$ & \\
\hline Median (IQR) & $3.4(2.99-3.82)$ & $4.01(3.5-4.83)$ & \\
\hline \multicolumn{3}{|l|}{ Actual FVC } & $<.001 *$ \\
\hline$n$ & 175 & 381 & \\
\hline Mean $\pm \mathrm{SD}$ & $4.31 \pm 0.8$ & $5.1 \pm 1.03$ & \\
\hline Median (IQR) & $4.15(3.71-4.78)$ & $4.89(4.27-5.91)$ & \\
\hline \multicolumn{3}{|l|}{$\mathrm{FEV}_{1} \mathrm{Z}$ score } & $.15 \dagger$ \\
\hline$n$ & 175 & 381 & \\
\hline Mean \pm SD & $-0.09 \pm 0.93$ & $0.04 \pm 1.02$ & \\
\hline Median (IQR) & $-0.18(-0.72$ to 0.48$)$ & $0.07(-0.65$ to 0.68$)$ & \\
\hline \multicolumn{3}{|l|}{ FVC Z score } & $.36 \dagger$ \\
\hline$n$ & 175 & 381 & \\
\hline Mean \pm SD & $-0.06 \pm 0.98$ & $0.03 \pm 1$ & \\
\hline Median (IQR) & $-0.14(-0.79$ to 0.56$)$ & $-0.02(-0.67$ to 0.74$)$ & \\
\hline \multicolumn{4}{|c|}{$\begin{array}{l}\mathrm{Z} \text { score analysis of } 18-50 \text {-year-old cohort by active duty status and standardized to age group } \\
(18-20,21-30,31-40, \text { and } 41-50 \text { y) and gender } \\
* \text { Wilcoxon rank-sum text } \\
\dagger t \text { test } \\
\text { Non- } \mathrm{AD}=\text { non-active duty } \\
\mathrm{AD}=\text { active duty }\end{array}$} \\
\hline
\end{tabular}

There were more PFTs completed in 2006 and 2007, but the non-AD population consistently had a higher percentage than the AD population for all years. The distribution of supranormal PFTS by age range is shown in Figure 2. A higher percentage of PFTs with supranormal values is seen in the 18-20-year age group but is evenly distributed between $\mathrm{AD}$ and non- $\mathrm{AD}$ persons. This is a consistent finding for the 20-, 30- , and 40-year age groups, with $7.6 \%, 7.2 \%$, and $7.1 \%$ of all patients supranormal, respectively, with decreasing percentages in older age groups. Distribution by ethnicity (Caucasians, African-Americans, and Hispanics) is shown in Fig. 3, where there are similar percentages for supranormal values for the $\mathrm{AD}$ and non- $\mathrm{AD}$ groups.

Notably, the non-AD population included more female than male studies: $86 \%$ female versus $14 \%$ male in the non-AD 18-50-year age group and $65 \%$ female versus $35 \%$ male in the non-AD 51-100-year age group. The AD population was comprised of a higher percentage of male patients (57\% male versus $43 \%$ female). Analysis for differences in PFT values $\left(\mathrm{FVC}, \mathrm{FEV}_{1}\right.$, and $\mathrm{FEV}_{1} / \mathrm{FVC}$ ) for both males and females between groups demonstrated significance for $\mathrm{FEV}_{1}$ and $\mathrm{FEV}_{1} / \mathrm{FVC}(P<.001)$. Post hoc analysis again yielded no significant difference when the gender-based AD 18-50-year age group was compared with the non-AD 18-50-year age group for both $\mathrm{FEV}_{1}$ and FVC.

\section{Discussion}

Minimal information has been previously published on the frequency or significance of supranormal PFTs. Understandably, if elevated values are found during the performance of spirometry in a symptomatic patient, this finding is not typically indicative of a disease process and 


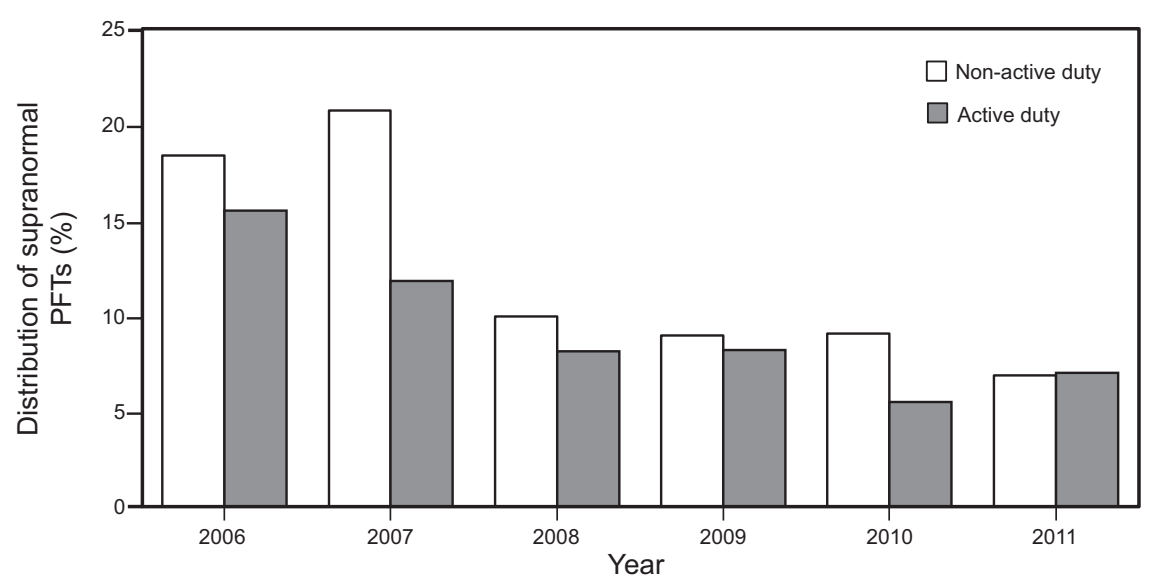

Fig. 1. Percentage of supranormal pulmonary function test (PFT) values divided by non-active duty and active duty per given year. Higher percentages are seen for each given year for the non-active duty persons.

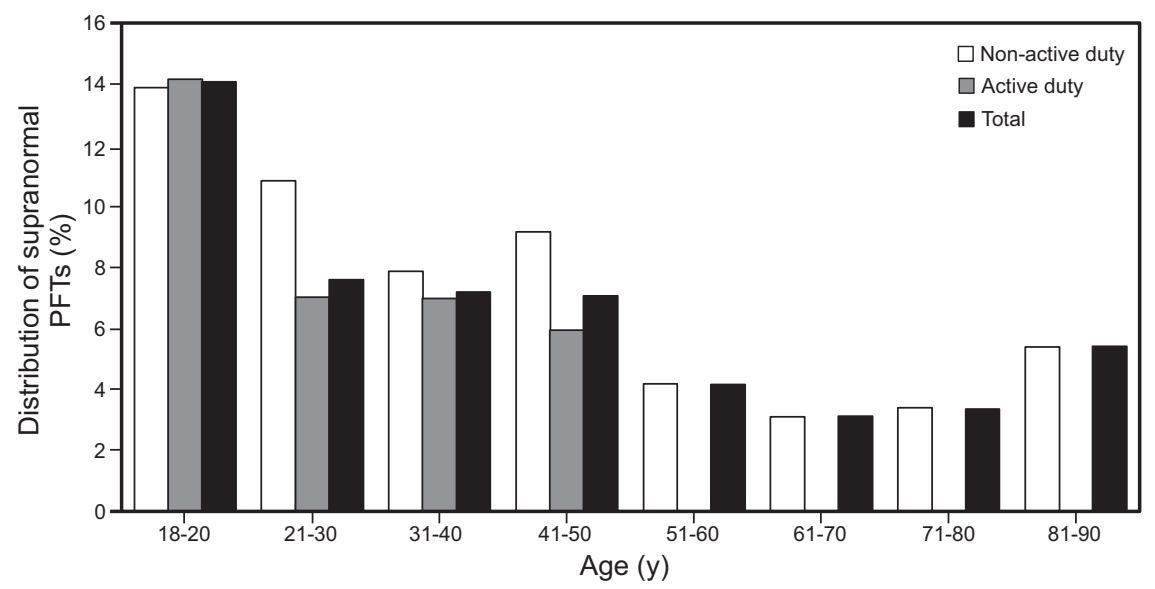

Fig. 2. Percentage of supranormal pulmonary function tests (PFTs) for each age group for both non-active duty and active duty persons. Higher percentages are seen in the 18-20-year age group but remain consistent for the next 3 age deciles.

reassures the clinician that an obstructive or restrictive process is not present. Based on current population studies and spirometry reference values (eg, NHANES III), the derivation of expected normal values should be closer to $100 \%$ of predicted because of normal population distributions. However, knowing the baseline spirometry value of any given patient can be important in determining the presence or absence of pulmonary disease, as it can identify individual changes in pulmonary function over time. Especially in a younger, more fit population, does a normal spirometry in the presence of symptoms represent active pulmonary disease? This study has begun to answer several questions regarding supranormal PFT values. First, supranormal values were a common finding across all age ranges in our population and did not favor a specific age group where more comprehensive reference values may be lacking. Second, differentiating between AD personnel and their non-active counterparts did not demonstrate an increased frequency of supranormal PFT values. On the ba- sis of this study, we have reservations about automatically defining the AD military population as having supranormal values on PFTs.

The joint American Thoracic Society/European Respiratory Society recommendations on pulmonary function testing and interpretation were published in 2005 and made several important changes. ${ }^{9}$ The primary change included incorporation of variances in the published reference equations from a higher percentage of minority populations. ${ }^{8}$ In addition, interpretation was changed to incorporate $95 \%$ CIs to define the lower limit of normal. There are multiple factors that can influence the performance of spirometry, and they are related primarily to patient effort and ability to consistently reproduce the forced expiratory maneuver. Incorrect height and age may drastically alter the predicted value, and thus incorrectly, the percent of predicted may be in the normal or supranormal range. Although both the upper and lower limits of normal for most reference equations are established, generally there is no clinical use of 


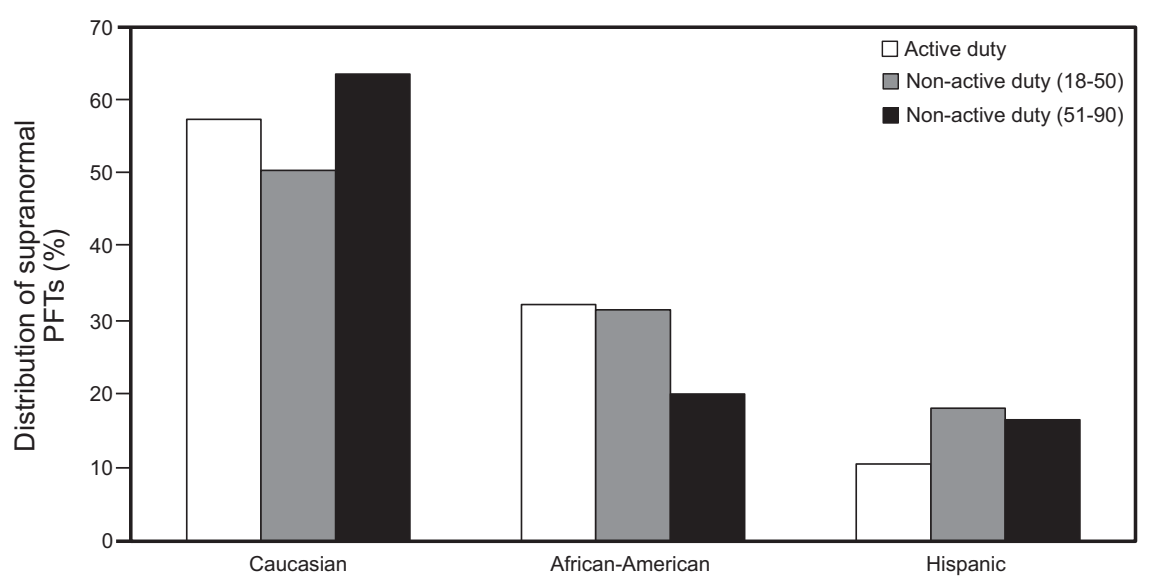

Fig. 3. Distribution of supranormal pulmonary function tests (PFTs) by ethnicity (Caucasian, African-American, or Hispanic) for the three study groups. Similar percentages were found for each ethnicity.

Table 4. Pulmonary Function Testing in Elite Athletes

\begin{tabular}{|c|c|c|c|c|c|c|c|c|c|}
\hline \multirow{2}{*}{ Citation } & \multirow{2}{*}{$n$} & \multirow{2}{*}{ Age (y) } & \multirow{2}{*}{ Height $(\mathrm{cm})$} & \multicolumn{3}{|c|}{ FVC } & \multicolumn{3}{|c|}{$\mathrm{FEV}_{1}$} \\
\hline & & & & Actual & Predicted & $\%$ Predicted & Actual & Predicted & $\%$ Predicted \\
\hline Maron $^{16}$ & 12 & 33 & 174 & 5.58 & 5.18 & 107.7 & NA & 4.20 & NA \\
\hline Hill $^{17}$ & 12 & 33 & 177 & 5.33 & 5.37 & 99.3 & 4.36 & 4.35 & 100.2 \\
\hline Bousanna $^{18}$ & 12 & 22 & 176.5 & 5.62 & 5.50 & 102.2 & 4.64 & 4.57 & 101.5 \\
\hline Kippelen ${ }^{19}$ & 13 & 22 & 179 & 6.12 & 5.58 & 109.7 & 4.95 & 4.64 & 106.7 \\
\hline $\operatorname{Ross}^{20}$ & 9 & 32 & 179 & 5.73 & 5.44 & 105.3 & 4.63 & 4.41 & 105.0 \\
\hline Denguezli $^{21}$ & 9 & 19 & 176 & 4.85 & 5.27 & 92.0 & 4.18 & 4.43 & 94.4 \\
\hline Mean & $($ Total $N=67)$ & 27 & 176.9 & 5.54 & 5.39 & 102.7 & 4.55 & 4.43 & 101.6 \\
\hline
\end{tabular}

Comparison of baseline spirometry values $\left(\mathrm{FEV}_{1}\right.$ and $\left.\mathrm{FVC}\right)$ in elite athletes (marathoners and triathletes)

the upper limit of normal in the interpretation of spirometry. It is presumed that a patient being evaluated for pulmonary disease with normal values for $\mathrm{FEV}_{1}, \mathrm{FVC}$, and $\mathrm{FEV}_{1} / \mathrm{FVC}$ would not have significant disease. In many instances, the evaluation for the presence of pulmonary abnormalities may end with a normal spirometry. In those evaluations in which there is concern for occupational disease, serial PFTs are used to detect significant clinical change. However, as the discussion in the American Thoracic Society guidelines adequately points out, there is a vast difference in the evaluation of healthy subjects and patients with disease or symptoms. Applying the same concept of "normal" based solely on PFT findings would be inappropriate, and the interpretation very much depends on the clinical question being asked. ${ }^{10}$

Early investigations suggested an increase in lung function during adolescence, especially noted in those individuals with high levels of activity. ${ }^{11,12}$ One particular group with supranormal values includes competitive swimmers due to their particular type of exercise. An Australian study of 8 swimmers compared with 8 runners showed higher $\mathrm{FEV}_{1}$ and $\mathrm{FVC}$ in the swimmer group, which were related primarily to an increase in chest wall width. ${ }^{13}$ This confirmed earlier findings in several other small studies of swimmers. ${ }^{14,15}$

Given the hypothesis that highly athletic individuals have supranormal PFT values, the published literature on PFTs in competitive athletes should provide ample information. Six published articles were identified that measured resting spirometry values in long-distance runners (both marathon and triathlon participants). ${ }^{16-21}$ These studies described primarily the effect of running on PFT values and provided baseline spirometry values in small groups of highly trained athletes. Table 4 provides the demographic information along with actual and predicted values for $\mathrm{FEV}_{1}$ and FVC. From this group of 67 athletes with a mean age of 27 years, the mean FVC was $102.7 \%$, and $\mathrm{FEV}_{1}$ was $101.6 \%$. None of the mean values from these 6 studies reached the $110 \%$ cutoff as defined in our study, although this group was younger ( 27 vs 31 y) than our AD population.

Because our study is retrospective in nature, there are several limitations to the data provided. Because the spirometers in our laboratory do not identify values outside 
the 95th percentile for the upper limit of normal, we had to establish a cutoff for review based on the percent of predicted, which showed a modest correlation with $90 \%$ and 95\% CI. Other factors such as the indication for spirometry and smoking history were not listed in the PFT report, and we were unable to distinguish between symptomatic and asymptomatic individuals. Interpretation of spirometry is limited without other pertinent clinical information such as symptoms or underlying lung disease. Additional potential biases include the comparison of $\mathrm{AD}$ military with dependents and retirees. We assumed an overall improved fitness for the $\mathrm{AD}$ group but did not have any direct measurements. Also, although the repeatability of the values within a given test is required by PFT standards, we were unable to determine in our cohort if the supranormal values could be repeated over time. Finally, there are limited large population studies with PFT reference values with which we can compare our data.

Another consideration that has been discussed is the role of spirometry screening for all military service members. Spirometry is currently not used as a screening tool in asymptomatic individuals prior to enlistment or commissioning into the United States Armed Forces. Current guidelines do not recommend "screening" for common lung diseases in the general population and limit surveillance to those individuals with potential occupational exposures. There are a multitude of confounding factors surrounding this issue, including cost, manpower, quality control, and timing of screening spirometry, that make such a proposition difficult to accomplish. The main reasons not to perform spirometry screening include: (1) the limited use of a screening test in an asymptomatic population, (2) the very small likelihood of developing future respiratory disease in this population, and (3) the burden of evaluating abnormal baseline tests that may affect military careers.

\section{Conclusions}

The assumption that AD military have elevated or supranormal PFT values by virtue of their AD status is not supported by this study. There is a fairly even distribution of supranormal values across all age groups, and there is no proof that more athletic AD military have increased values over their non-AD counterparts. Although a prospective evaluation of a larger group of AD military is warranted, current practice standards should interpret PFTs according to published guidelines and not assume an underlying disease process in AD military or elite athletes when PFTs are found to be within normal limits.

\section{REFERENCES}

1. Morris MJ, Grbach VX, Deal LE, Boyd SY, Morgan JA, Johnson JE. Evaluation of exertional dyspnea in the active duty patient: the diagnostic approach and the utility of clinical testing. Mil Med 2002; 167(4):281-288.

2. King MS, Eisenberg R, Newman JH, Tolle JJ, Harrell FE Jr, Nian H, et al. Constrictive bronchiolitis in soldiers returning from Iraq and Afghanistan. N Engl J Med 2011;365(3):222-230.

3. Dodson DW, Zacher L, Lucero P, Morris M. Study of active duty military for pulmonary disease related to environmental dust exposure (STAMPEDE). Am J Respir Crit Care Med 2011;183:A4784.

4. Sheel AW. Respiratory muscle training in healthy individuals. Physiological rationale and implications for exercise performance. Sports Med 2002;32(9):567-581.

5. McKenzie DC. Respiratory physiology: adaptations to high-level exercise. Br J Sports Med 2012;46(6):381-384.

6. Rundell KW, Wilber RL, Szmedra L, Jenkinson DM, Mayers LB, $\mathrm{Im}, \mathrm{J}$. Exercise-induced asthma screening of elite athletes: field versus laboratory exercise challenge. Med Sci Sports Exerc 2000;32(2): 309-316.

7. Millward D, Paul S, Brown M, Porter D, Stilson M, Cohen R, et al. The diagnosis of asthma and exercise-induced bronchospasm in Division I athletes. Clin J Sport Med 2009;19(6):482-486.

8. Hankinson JL, Odencrantz JR, Fedan KB. Spirometric reference values from a sample of the general U.S. population. Am J Respir Crit Care Med 1999;159(1):179-187.

9. Pellegrino R, Viegi G, Brusasco V, Crapo RO, Burgos F, Casaburi $\mathrm{R}$, et al. Interpretative strategies for lung function tests. Eur Respir J 2005;26(5):948-968.

10. Lung function testing: selection of reference values and interpretative strategies. American Thoracic Society. Am Rev Respir Dis 1991; 144(5):1202-1218.

11. Andersen KL, Magel JR. Physiological adaptation to a high level of habitual physical activity during adolescence. Int Z Agnew Physiol 1970;28(3):209-227.

12. Dempsey JA. J. B. Wolffe memorial lecture. Is the lung built for exercise? Med Sci Sports Exerc 1986;18(2):143-155.

13. Yost LJ, Zauner CW, Jaeger MJ. Pulmonary diffusing capacity and physical working capacity in swimmers and non-swimmers during growth. Respiration 1981;42(1):8-14.

14. Vaccaro P, Clarke DH, Morris AF. Physiological characteristics of young well trained swimmers. Eur J Appl Physiol Occup Physiol 1980;44(1):61-66.

15. Armour J, Donnelly PM, Bye PT. The large lungs of elite swimmers: an increased alveolar number? Eur Respir J 1993;6(2):237-247.

16. Maron MB, Hamilton LH, Maksud MG. Alterations in pulmonary function consequent to competitive marathon running. Med Sci Sports 1979;11(3):244-249.

17. Hill NS, Jacoby C, Farber HW. Effect of an endurance triathlon on pulmonary function. Med Sci Sports Exerc 1991;23(11):1260-1264.

18. Boussana A, Matecki S, Galy O, Hue O, Ramonatxo M, Le Gallais D. The effect of exercise modality on respiratory muscle performance in triathletes. Med Sci Sports Exerc 2001;33(12):2036-2043.

19. Kippelen P, Caillaud C, Robert E, Connes P, Godard P, Prefaut C. Effect of endurance training on lung function: a one year study. Br J Sports Med 2005;39(9):617-621.

20. Ross E, Middleton N, Shave R, George K, McConnell A. Changes in respiratory muscle and lung function following marathon running in man. J Sports Sci 2008;26(12):1295-1301.

21. Denguezli M, Ben Chiekh I, Ben Saad H, Zaouali-Ajina M, Tabka Z, Abdelkrim Z. One year endurance training: effects on lung function and airway inflammation. J Sports Sci 2008;26(12):1351-1359. 